\title{
It is emergent: five propositions on the relationship between creative consumers and technology
}

\author{
Philip DesAutels and Esmail Salehi-Sangari \\ Division of Industrial Marketing, \\ KTH, Royal Institute of Technology, \\ Valhallavägen 79, 10044 Stockholm, Sweden \\ E-mail:philip@wuhwuhwuh.com \\ E-mail: ess@indek.kth.se
}

\author{
Pierre Berthon and Tamara Rabinovich \\ McCallum Graduate School of Business, \\ Bentley University, \\ 175 Forest St., Waltham, MA 02452, USA \\ E-mail: pberthon@bentley.edu \\ E-mail: trabinovich@bentley.edu
}

\section{Leyland Pitt*}

Beedie School of Business,

Simon Fraser University,

500 Granville Street,

Vancouver, BC V6C 1W6, Canada

E-mail: leyland_pitt@sfu.ca

*Corresponding author

\begin{abstract}
Drawing on four research papers and case studies, this paper explores the interaction between creative consumers and technology. While prior research has taken either a technology 'push' stance (technology shapes consumers) or a 'pull' posture (technology results from identifying consumer needs), the view adopted here is that the interplay between technology and consumers is mostly non-linear and emergent. From Facebook, where the consumer is the product, to user generated information systems (UGIS) where the consumers creates the product; and from Rev Billy who uses technology to creatively deconstruct consumption to mobile phones where technology is enabling the creative consumer, there is much to learn about how technology and creative consumers interact. Using these case studies five researchable propositions regarding technology and creative consumers are developed and illustrated, and it is hoped that these propositions can serve as guides to future research in this interesting and important developing domain of scholarship.
\end{abstract}

Keywords: creative consumers; technology; interaction; research propositions.

Reference to this paper should be made as follows: DesAutels, P., Salehi-Sangari, E., Berthon, P., Rabinovich, T. and Pitt, L. (2014) 'It is emergent: five propositions on the relationship between creative consumers and technology', Int. J. Technology Marketing, Vol. 9, No. 1, pp.72-85. 
Biographical notes: Philip DesAutels is an adjunct member of faculty in the Division of Industrial Marketing, (KTH) Royal Institute of Technology, Stockholm, Sweden. He holds a $\mathrm{PhD}$ in Industrial Marketing from Lulea University of Technology, and has published in such journals as Business Horizons, Psychology and Marketing, and the Journal of Public Affairs.

Esmail Salehi-Sangari is the Chair of the Division of Industrial Marketing, (KTH) Royal Institute of Technology, Stockholm, Sweden. He was formerly chair of the same division at Lulea University of Technology, and has published in such journals as Industrial Marketing Management, European Journal of Marketing, and Technovation.

Pierre Berthon is a Clifford Youse Professor of Marketing in the McCallum Graduate School of Business, Bentley University, Waltham MA. He has published in journals such as Sloan Management Review, Journal of Service Research, and Journal of Management Studies.

Tamara Rabinovich holds an MS in Education of Technology and Science from the Technion, Israel Institute of Technology. She earned her doctorate in the Educational Media and Technology program at Boston University's School of Education, where her research focused on technology and distance learning.

Leyland Pitt is the Dennis F. Culver EMBA Alumni Chair of Business in the Beedie School of Business, Simon Fraser University, Vancouver, Canada. He has published in journals such as California Management Review, Journal of the Academy of Marketing Science, and MIS Quarterly.

\section{Introduction}

The term technology is usually used to refer to the making, modification, usage, and knowledge of tools, machines, techniques, crafts, systems, and methods of organisation, in order to solve problems or perform specific functions. The management literature, and marketing especially, has almost exclusively viewed technology as a means to the end of meeting user requirements. Marketers see technology as a, and increasingly the, means by which needs and wants are met. This is an unwarrantable misunderstanding as Berthon et al. (2005) point out, and an etymological review of the word technology suggests a very different meaning from the popular, instrumental view of technology as a means to an end. From this perspective, technology is seen as an active force, and thus technology and society are reciprocally linked, such that the trajectory of each is co-dependent and emergent. Indeed, existing views that either see technology as a 'pushing' force (technology shapes consumers) or as 'pulling' (technology is created in response to consumer needs), the perspective adopted here is that the interplay between technology and consumers is mostly non-linear and emergent.

Technology is on the one hand the product of people and on the other hand their producer. The former statement is self-evident - people develop and employ technology to achieve certain goals. However, technology, is no mere means, it is a way of revealing, of bringing forth, of constructing new realities. Berthon et al. (2005) note 'technology 'produces' people' in that it enables and influences how people enact their self-identities, 
how people interact with one another, and how they interact with the wider natural environment.

In the modern age, technology was predominantly produced by organisations (mostly in the form of large companies), and mostly in response to articulated consumer needs. In more recent times - whether we call this era the post-modern age (e.g., Pitt et al., 2007) or the information age matters little - consumers are increasingly creating technology themselves and for themselves. This may be from scratch, or more typically in the form of the proprietary offering of firms being modified, hacked, changed or repurposed. We have certainly entered the age of the creative consumer, defined as an individual or group, who adapts, modifies or transforms a proprietary product, service or idea (Berthon et al., 2007). The creative consumer phenomenon makes the interaction between consumers and technology even more complex, but it also offers intriguing research possibilities. In this paper, based on four case studies of the interaction between consumers and technology, we suggest propositions that scholars can consider in studying this interaction.

The case studies have been chosen specifically because they illustrate the various ways in which consumers interact with technologies, albeit in very different contexts. The case of Reverend Billy and the Church of Life After Shopping's shows how humour is used to liberate citizens' thinking around the three C's of US political ideology: church, capitalism and consumption. The Reverend adroitly integrates both old and new media into an integrated whole to influence the very consumers who have been shaped by these tools. In the next case study, user generated information systems (UGIS), we explore how a conjunction of low-cost, powerful and omnipresent information technologies is enabling shifts in IT user capabilities, and changing how individuals see products, and the challenges for organisational information systems providers is profound. The third case that of Facebook and the Facebook videos - explores the paradoxes of consumer-service interaction. It shows how consumers almost always hold ambivalent attitudes to the services they use, partly because consumers both use and are used by the service. Services such as Facebook both facilitate and change the behaviour of consumers, and while they mediate social interactions, they simultaneously drive social actors. Finally, the focus is on sustainable development and fair globalisation with particular reference to how labour in international supply chains is affected by connectivity. The case provides strong evidence for link between national culture, e-readiness and fair labour practices. The implications for global brands, and the customers who consume them, are significant.

\section{The four case studies}

\subsection{Reverend Billy and the Church of Life after Shopping (Berthon et al., 2011a)}

With the rise of new media, it is easy to overlook, not just old media, but mummery - the arcane medium of the flesh - street performances, stage shows, plays and carnivals. The Church of Life After Shopping (formerly known as the Church of Stop Shopping) is an activist performance group based in New York City, led by Reverend Billy, the stage name of Bill Talen. Using the form of a revival meeting, on sidewalks and in chain stores, Reverend Billy and his gospel choir exhort consumers to abandon the products of 
large corporations and mass media. Reverend Billy also preaches a broader message of economic justice, environmental protection, and anti-militarism, and protests against sweatshops. Although it focuses on street theatre activities, the church has also appeared on stage and has toured internationally.

The Reverend Billy offers us two important insights: first, how to use humour to liberate people's thinking around the three pillars of US political discourse, namely church, capitalism and consumption; and second, how to integrate the medium of the flesh with new media. Reverend Billy judiciously combines the arts of mummery and new media to free consumers from the dominant ideology of US political interlocution.

\subsection{UGIS: user generated information systems}

Since their inception, information systems have been owned and managed by organisations, who decide on what information technologies users need, and how they use these technologies. They then purchase these technologies (desktop and laptop computers, mobile phones and pagers), and also provide the software that run on these. However, the advent of new technologies such as smartphones and tablet computers, which many people purchase themselves, using software they have obtained themselves, is changing the nature of organisational information systems in a fundamental way. This trend toward 'BYOD', or 'bring your own device', where individuals use their own devices to access the organisation's information and do their work, has profound implications for the management, and even the existence, of formal management information systems within organisations.

People from around the world are bringing together a variety of information technologies - devices, services, applications, networks and information - to create personal information systems. This emerging phenomenon is enabled by a convergence of inexpensive, powerful and ubiquitous devices and applications connected through global networks, motivated by an open ideology and enacted by 'prosuming' users according to DesAutels (2011). This author argues that the resulting shift in user capability brought about by the UGIS phenomenon is changing how individuals see products. "Users building UGIS are looking beyond the products themselves, and even beyond the services those products deliver, to the services they enable. This has substantial impact on the producers of these technological components, who-still widely unawares-are seeing their role transmogrified from producer to provider, and the fundamental nature of their products shifted from ends to means" (p.186). The challenge that producers-cum-providers of technology face, then, is how to adapt and innovate in the face of UGIS.

\subsection{Facebook and the Facebook videos}

Companies spend millions of dollars researching consumers, consumer attitudes to brands, and consumer uses of products. Yet, the irony is that consumers are now doing this research themselves and posting their material to video sharing sites such as YouTube. Berthon et al. (2011b) used the BASIC IDs framework (Lazarus, 1989, 1997; Cohen, 1999) for dimensional qualitative research to deconstruct consumer-generated videos to yield valuable insights into the paradoxes of consumer-service interactions. Using three consumer generated ads about the social networking site Facebook these authors explored the paradoxes of consumer-service interaction; namely consumers' 
ambivalent attitudes to the service, how the consumer uses and is used by the service, how the service both facilitates behaviour and changes behaviour, and how the service mediates social interactions yet drives social actors.

\subsection{Culture and e-readiness}

Firms are continually incented to reduce costs. They can do this by becoming more efficient or by externalising costs. The socially and geographically distant ends of global supply chains are frontier economies where externalising is easier because the externalised costs such as those placed on workers through low wages, unsafe conditions, and unfair practices are shaded from view. In addressing the important issue of sustainable development and fair globalisation a number of authors (e.g., Berthon et al., 2008a, 2008b) have focused attention on the impact that connectivity has on labour in the global supply chain. Drawing upon a number of large international surveys there is strong evidence for a relationship between a nation's subjective values with national-level, objective measures of connectivity and labour equity, as well as an interesting link between connectivity, cultural values and the equity of a nation's workforce.

Based on these four cases, we suggest five research propositions for examining the interaction between technology and creative consumers. These propositions are summarised in Table 1, and expanded upon in the following section.

\section{Technology and the creative consumer: five propositions}

The brief cases above, and the observations made in them lead us to make five propositions that those interested in further examining the interplay between technology and creative consumers might find to be useful research guidelines. We now outline and discuss each in turn.

Table 1 The five propositions

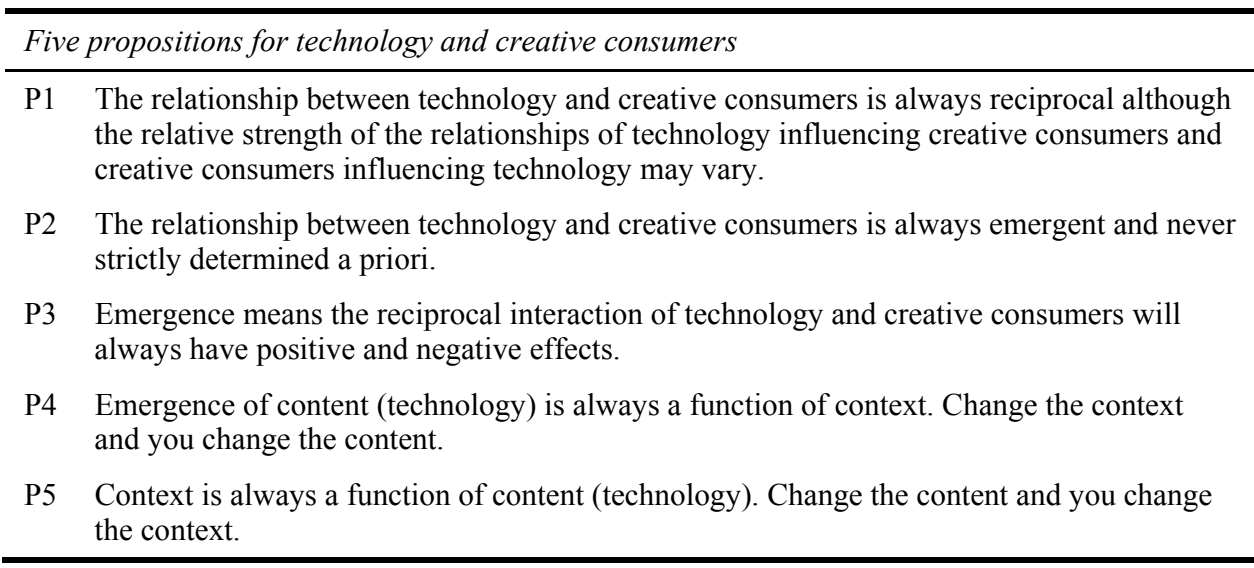

$\mathrm{P}_{1} \quad$ The relationship between technology and creative consumers is always reciprocal although the relative strength of the relationships of technology influencing creative consumers and creative consumers influencing technology may vary. 
Each of the studies presented here confirms our underlying supposition that "technology is never purely technological: it is also social" and that the "social is never purely social: it is also technological" [Bijker and Law, (1992), p.305]. Looking across all of them however, it is evident that the relationship between technology and creative consumers is more than a one-way transaction - the relationship is an interaction. It is active, living, moving, and ongoing. In short, it is imbued with technological momentum (Hughes, 2004) whereby creative consumers and technology are each driving the other along. This resonates with the notion of 'velocity coupling' (McCarthy et al., 2010), where the rate and direction of change in how a market consumes (uses) a technology is tightly coupled to the rate and direction of change in the technology itself. These tightly coupled systems result in relatively continuous, constant, and significant causal effects between the consumer and the technology. Thus, the relationship between technology and creative consumers can be thought of as a reciprocal dance of technology influencing creative consumers influencing technology and so on. But the dance has a strange meter because the influence of technology on creative consumers and creative consumers on technology is often lopsided. This reciprocal and asymmetric nature of the relationship is visible in each of the studies:

(The Reverend Billy case): We join the Reverend Billy in the middle of a relationship... Technology has been enabling consumerism for a very long time. In recent years, the internet and new media technologies have taken this to a new level. To understand the magnitude of this change, one need only consider that in 1964 consumers saw 76 advertisements a day, while today, they bombarded by over 3,000 (Shenk, 1997). These technologies have also changed the way consumers shop. Now, convinced as we are from three thousand ads a day that we are lacking, unfashionable, ill or woefully in need, we find a world of products is just a few mouse clicks and a UPS truck away: the combined result, a massive global increase in consumerism (technology influencing creative consumers). But, the internet and social media tools are open for anyone to use. They empower the individual as much as they do the marketer. Enter Reverend Billy in his crusade against consumerism. His potent form of activism was transformed from local entertainment into a global phenomenon when he integrated the power of social media into his repertoire. In the process, Billy transformed the internet technologies used to create consumers into the tools to fight consumerism (creative consumers influencing technology) and then through his activism, he has used these technologies to influencing global attitudes about consumerism (technology influencing creative consumers).

(The case of UGIS): The phenomenon of UGIS is a stable position in the reciprocal dance of technology and creative consumers - an obduracy (Bijker and Law, 1992). It is the outgrowth of many different interactions: the growth of prosumption (Toffler, 1980) (creative consumers influencing technology), the development of interoperable and composable technologies (Illich, 1973) (creative consumers influencing technology), the emergence of a pull ideology (Hagel and Brown, 2008), and the ubiquity of networks and devices (technology influencing creative consumers).

$\mathrm{P}_{2}$ The relationship between technology and creative consumers is always emergent and never strictly determined a priori.

Certain sociotechnical configurations - technology applied to a use in a given context gain obduracy or stable structure (Bijker and Law, 1992). Some so much so that they become fixed or enframed (Heidegger, 1977) into nearly immutable and enduring forms - the hardcover book or the internal-combustion engine automobile for example. Yet 
even these most obdurate forms are not as fixed as would appear as the growing dominance of the Amazon e-book (Miller, 2010) and the hybrid Toyota Prius (Gregory, 2011) show. Stability is fleeting. Change is imminent, emergent and often unforeseen.

The changes in the book and the automobile and more generally, the technological momentum present in all sociotechnical systems that pulls them from points of obdurate equilibrium to new unanticipated configurations stems from the emergent potential embodied in them (Heidegger, 1977). This potential is not inherent in either technology or creative consumers themselves, but rather it exists in the interactions of technology's content embedded in creative consumers' context (Polanyi, 2002/1944). Change one and you create the potential for change in the other.

Technology is often built with a purpose in mind, with outcomes and impacts evaluated and assessed, but as the examples below show, it is seldom the case that technologies are used in the way intended or that the impacts of a technology were what was foreseen. The interactive relationship between technology and creative consumers emerges forth unpredictably from a sea of potentiality.

(The case of culture and e-readiness): The nature of business across the globe was transformed by the general availability of personal computers and mobile phones connected together via the internet. Indeed, the very measure of connectivity used in these articles and cases is meant to serve as a country-by-country measure of that impact. Business demands have driven lower prices, ease of use, and greater ability and this in turn has led to the state we are in now where more than half of the world's population has a mobile phone and one third has internet access. But, at the distant edges of the supply chain, these communications technologies take on an unexpected and unforeseen role they become global equalisers and in the process they have changed the nature of the technology and of creative consumers. Workers are no longer forced to acquiesce to unfair and unsafe working conditions with little recourse, a photo on a mobile phone can easily find its way to the evening news and with that, global corporations can be transformed.

(The case of the Facebook videos): Social networks were created as a way for people to bring their real lives online, scaled up and out as only internet technologies can do. Social media is a way for them to gain a public voice in mass media. The effect of these two technologies has been quite unexpected and unplanned. For Gen Y [the generation born between the early 1980 s and the early years of the new millennium, e.g., Hill (2002)], it has redefined the nature of their social interaction. They define themselves with and within social networks, they tell their stories through social media. At the same time Gen Y has unexpectedly transformed these technologies. Social media has become an arbiter of reality-defining relationships in the real world rather than describing them. An unexpected consequence of social technologies has been the transformation of a generation into online entities and also the transformation of virtual worlds into real.

(The case of UGIS): The phenomenon of UGIS is emergent, unplanned and, with the exception of the research presented here, still not even widely recognised; yet almost every one of us is a beneficiary - easily creating complex information systems without a moment's thought. The history of events from the technical design choices made in the development of the internet to the emergence of prosumption (itself a social response to consumerization), to the encapsulation and 'blackboxing' (Latour, 1987) of the complex, to the global availability of inexpensive and powerful devices connected together in global networks, is a lesson in the unintended effects of the relationship between 
technology and creative consumers. The phenomenon is itself an example of the relationship's emergent nature and power.

$\mathrm{P}_{3} \quad$ Emergence means the reciprocal interaction of technology and creative consumers will always have positive and negative effects.

Sociotechnical systems left on their own would remain stable, but this is seldom the case. Outside forces are constantly intruding and as they do, old obdurate configurations destabilise, giving way to new unanticipated ones. Change comes in three forms:

1 Entrepreneurs create and then introduce technologies into contexts; creative consumers adopt and adapt both themselves and the technology, and as a result the sociotechnical system gains momentum (Latour, 1987).

2 Technologies get passed between people, cultures and contexts; the heterogeneous needs of the recipients lead to conflict, difference or resistance in what technology is, what it should be and how it is used as a result. Technology and creative consumers are shaped and reshaped and technological momentum occurs (Bijker and Law, 1992).

3 The context of creative consumers can change and with that change, technology is reinterpreted, reconfigured or replaced. Again, the sociotechnical system gains momentum (Hagel and Brown, 2008).

Each of these forces of change - entrepreneurs, motion and contextual shift - creates an interaction that is largely unplanned, each introduces new degrees of freedom (Polanyi, 1970) and therefore each opens up the possibility of realising new emergent potential (Heidegger, 1977). The configurations that emerge from the resulting cycle of destabilisation and stabilisation are often novel and unanticipated, their consequences, as the examples below show, may be positive, neutral, negative or some combination of all three.

(The case of culture and e-readiness): Moore's law, mass production, ubiquitous networks, standard and easy to use applications transformed notebook computers and mobile phones from niche products for business elites and technology enthusiasts to globally desired mass-market products. As the work on e-readiness and connectivity shows, workers at the ends of global supply chains have been unintended beneficiaries (positive effect) of the emergence of ubiquitously available communications technology. At the same time, the same global demand and rapid product cycles that made this ubiquity available have created a massive new problem - 40 million tons of e-waste a year (Royle, 2005) (negative effect).

(The case of the Facebook videos): Social networking has literally transformed the social structure of the planet - Facebook, the globally dominant social network has almost a billion active users who share billions of messages every day on the service. More than $20 \%$ of all time spent online is in social networks (Nielsen, 2010). The effect is a more connected world that has benefits as the e-readiness case shows (positive effect). At the same time, social networking technologies are transforming a generation. The reality of generation $\mathrm{Y}$ is now defined in and by the social networks they participate in and it is mutable, always in flux; their real world a mirror of the virtual and the full effects (positive, negative and/or neutral) of this are yet to be fully determined. While some may be positive, this study and others note that the disconnection and distance that 
the virtual world creates is having substantial negative effects such as increased narcissism (Twenge and Campbell, 2009) and cyber bullying (Li, 2007).

$\mathrm{P}_{4}$ Emergence of content (technology) is always a function of context. Change the context and you change the content.

The instability that inheres in sociotechnical systems means that the potential for change is always imminent. A change to context leads to a change in technology and vice-versa. The context in which a technology is used constrains the potentiality of technology. Polanyi (1970) offers a useful model for conceptualising this. He suggests that we think of sociotechnical systems as hierarchies of transcendence. Building on this, we can think of any given sociotechnical configuration as being the product of a lower level technology and the context at hand. The lower level technology defines the range of possibilities (a possibility boundary); the context at hand constrains the realm of possibilities for use of that technology. The emergence of a given sociotechnical system is therefore bounded by technology's potential and constrained by the creative consumer's context. Change the context, and you change the constraints thereby freeing some possibilities to emerge from a technology while constricting others.

(The case of the Reverend Billy): The case of Reverend Billy highlights the transformative power of context. In 1999 when Billy Talen founded his activist ministry, social media technologies were becoming established - but their use was primarily as a way for users to build online social networks and publish their own content. As Billy's efforts grew, the role of social media changed. It was soon co-opted by companies as a marketing channel and in the process social media was redefined; the marketing context let to a technology shift in social media. Not long after social media's cooption as a platform for marketing, Billy co-opted the co-opted. From his context as activist, social media was transformed again, but this time into a powerful platform upon which to evangelise the anti-commercial message.

(The case of UGIS): UGIS presents a wonderful example of layers of contextual influence on technology. The history of the guiding principles of the internet and the web and the open ideology have their roots in the social movement of the 1960s and 1970s (c.f., Illich, 1973; Toffler, 1980). This provided the context for the emergence of an open and interoperable PC and mobile revolution. This technology shaped how people expected systems to work, and it changed how users used those systems. Soon everyone was technologically enabled. This provided the last bit of context needed to enable the emergence of aggregators such as the iPhone which allow anybody to create complex information systems and thus at many levels in the history of the UGIS phenomenon, context has shaped technology.

$\mathrm{P}_{5}$ Context is always a function of content, change the technological content and you change the societal context.

To recapitulate, instability inheres in sociotechnical systems and that means that change is imminent. But, now take technology's perspective. A given technology creates a possibility boundary. It defines all of the possibilities that might be. If we assume context is rigid then context limits how many possibilities can be enacted. If we consider instead that context is malleable, then the possibility boundary of the technology defines a range of potential contexts that might emerge. In other words, technology's potential creates degrees of freedom for the context to shift; it creates an opportunity space. This is both empowering in that many possibilities are opened up with new technologies and limiting 
because lacking a necessary technology such as electrical power may severely limit the range of context possibilities.

In 1979 personal computers were just emerging, there were just a few thousand mobile phones worldwide, and there were less than 1000 computers connected to the internet. By 2007, 30 million notebook computers were sold, 3.3 billion people had mobile phones (ITU, 2010), and Google alone reportedly had one million servers attached to the internet (Hidas, 2007) (technology). This massive shift in technology has had innumerable impacts on creative consumers. Unintended consequences such as the creation of 40 million tons of e-waste a year (Royle, 2005) contributed to global concerns over issues of sustainability and this led to a contextual shift - creative consumers demanded more sustainable produced laptops (context). The massive availability of portable computing devices (technology) led to a reshaping of creative consumers (context).

(The case of e-readiness): The rapid diffusion of communications technology - more than $50 \%(3.7 \mathrm{Bn})$ of the world's population has a mobile phone, almost one third ( $2 \mathrm{Bn})$ have access to the internet, 1.2 billion have a personal computer - has had a major impact on the global context (technology). As these technologies diffuse into disconnected corners of world, they are having a connecting effect, not just at the technical level but also at the social level. Communications technology is bringing the shaded ends of the supply chain into full view of the world. This change in technology has changed expectations and practice. Consumers now demand that the people producing the products they buy are treated fairly and equitably (context), when they are not (as Nike found out), it can mean hurt a brand. Producers are now responsible for not only their employees but also for their suppliers too (context). Increased communications (technology) has fundamentally changed global equity (context).

\section{Research discussion}

\subsection{Observations on the relationship between technology and creative consumers}

To reiterate, the abstractions of social and technical do not stand on their own, rather they are part of a whole: creative consumers embedded in technology, technology embedded in creative consumers. The momentum and trajectory of each is reciprocally linked to the other. To understand one, calls for examining it in the context of the other. The methodological approach used in this research has proven itself effective towards this end. Applied as it was, it provided the vantage points needed to disentangle the convoluted whole thereby gaining insight into the imbricated relationship between technology and creative consumers. Beyond the five propositions presented above, several general observations about technology's influence on creative consumers and creative consumers' influence on technology stand out:

\subsubsection{Technology shapes creative consumers}

First, technology enables and influences how people enact their self-identities. Second, technology changes how people interact with one another, and enables the possibilities of new types of community, while shaping the development and evolution of extant social 
groups. Third, technology enables scale and awareness far beyond the human capability. Fourth, through each of the above, technology changes how people interact with the wider environment. Fifth, technology defines the realm of what is possible.

\subsubsection{Creative consumers shape technology}

First, each creative consumer provides the context within which technology emerges and therefore the constraints on what can and will emerge within that creative consumer. That is, creative consumers define what is probable from the possible. Second, different societies provide different contexts leading to different revelations. As a result, the technology created by any given creative consumers and the way in which any given technology is used by that creative consumer may vary widely from creative consumer to creative consumer. Third, each creative consumer is in a constant struggle between the inertia of fixed or enframed (Heidegger, 1977) understanding of a technology and the emergent revelations of technology's potential being wrought by bricoleurs (Lévi-Strauss, 1966).

\subsection{Observations on the influence of the individual}

The shift to a service-based economy and the growth of outsourcing of everything from IT to childcare attests to the advanced level of separation between production and consumption that modern creative consumers have achieved at almost every level (Firat et al., 1995; Toffler, 1980); the evidence of this is all around us. One need only walk the isles of a Wal-Mart or a Tesco store today to see that every element of life has been processed, packaged and turned into a ready-to-use and ready-to-consume product. What is less evident is that we are at the same time in the midst of the re-emergence of the consumer as producer and this has a direct and unforeseen impact on this research.

Toffler formally introduced the notion of the 'prosumer', a portmanteau of producing consumer, as someone who works outside of the formal economic system, producing for self-consumption (Toffler, 1983). The emergence of prosumption to the mainstream of modern life is related to both technology's enabling effect (DesAutels, 2011) and a societal context within which individuals expect to be able to produce rather than just to consume (Hagel and Brown, 2008; Toffler, 1983; Xie et al., 2008).

In each of the studies presented here we find the prosumer working as an active "participant in the customization of his/her world" (Firat, et al., p.50), their behaviour influenced and enabled by technology and at the same time fundamentally influencing and reshaping it. The result? The emergence of the prosumer is altering the relationship between technology and creative consumers, adding to the technological momentum and to the uncertainty of outcomes. The ideology of prosumption as a potential third force alongside technology's influence on creative consumers and creative consumers' influence on technology as a contributor to the unintended pleotropic consequences of technology's impact on creative consumers and of creative consumers' impact on technology was unforeseen. To better understand it will take further research. 


\section{Limitations}

As with all research, the research presented here is not without limitations. These can be broke down into two major areas: the studies upon which this research is built and meta-research methodology. Turning first to the studies upon which this research is built, there are several limitations of note. First, it is self-evident that they are themselves stand-alone research projects and as such each has limitations that are duly identified and addressed within each study respectively. None of these limitations, either on their own or taken together impacts the work presented here in a substantive way. Next, the fact that each study had to stand on its own means that for each, a compromise was struck between the goals of the individual study and the goals of the current paper. The impact of this is to limit to some extent the insights gained from each study towards the larger goal of this paper. Fortunately, the breadth of subjects, research methodologies, and paradigmatic perspectives (hard/soft, technological/social determinism) provided coverage that ameliorated this limitation and as the findings above show kept these compromises from substantively impacting the observations of this paper. Finally, only four studies were used in this research, additional investigation is therefore called for to validate the findings discussed here.

Taking the position we hold above that there is determinism afoot, that is technology changes creative consumers and creative consumers change technology in ways that are not isolated nor strictly independent, then the question we face in researching the relationship between technology and creative consumers is: How? Reducing the whole of the relationship between technology and creative consumers to a sum of its parts is probably not feasible nor is it necessary. If we step back from the hard reductionist edge of determinism to a more centrist soft position as proposed here, then we can likewise step away from this seeming conflict between these two views and treat them instead as two lenses through which to examine the same relationship.

To gain any understanding of the relationship between technology and creative consumers we need to somehow disentangle specific interactions. This is where the yin and yang of technological determinism and social determinism come into play. Each provides a vantage point, the view of technology's impact on creative consumers or the view of creative consumers' impact on technology. Each of these contrapositions lets us see something of the relationship we seek to understand. By careful choice, we gain resolving power to see among the convolutions the specific interaction we want to describe. How much resolving power remains to be seen, but based on the results of this research project, the resolving power of the methodology seems promising. The conceptual solution to this problem of incommensurability we offer therefore is that technological and social determinism are perspectives on reality rather than reality per se and as such if we use them in the way proposed here, they become useful vantage points from which to conduct research into the relationship between technology and creative consumers in a way that provides useful insight for marketers and managers. 


\section{References}

Berthon, P.R., Fischer, K. and DesAutels, P. (2011a) 'From mummers to new media: captivity, liberation, and the church of life after shopping', Journal of Public Affairs, Vol. 11, No. 3, pp.181-187.

Berthon, P.R., Pitt, L.F. and DesAutels, P. (2011b) 'Unveiling videos: consumer generated ads as qualitative inquiry', Psychology \& Marketing, Vol. 28, No. 10, pp.1044-1060.

Berthon, P.R., Hulbert, J.M. and Pitt, L.F. (2005) 'Consuming technology: why marketers sometimes get it wrong', California Management Review, Vol. 88, No. 1, pp.110-128.

Berthon, P.R., Pitt, L.F., Berthon, J-P., Campbell, C. and Thwaites, D. (2008a) 'E-relationships for e-readiness: culture and corruption in international eB2B', Industrial Marketing Management, Vol. 27, No. 1, pp.83-91.

Berthon, P.R., Pitt, L.F., Cyr, D. and Campbell, C. (2008b) 'E-readiness and trust: macro and micro dualities for e-commerce in a global environment', International Marketing Review, Vol. 25, No. 6, pp.700-714.

Berthon, P.R., Pitt, L.F., McCarthy, I. and Kates, S.M. (2007) 'When customers get clever: managerial approaches to dealing with creative consumers', Business Horizons, Vol. 50, No. 1, pp.39-47.

Bijker, W.E. and Law, J. (1992) Shaping Technology/Building Society: Studies in Sociotechnical Change, The MIT Press, Cambridge, MA.

Cohen, R.J. (1999) 'What qualitative research can be', Psychology \& Marketing, Vol. 16, No. 4, pp.351-367.

DesAutels, P. (2011) 'UGIS: understanding the nature of user-generated information systems', Business Horizons, Vol. 54, No. 3, pp.185-192.

Firat, A.F., Dholakia, N. and Venkatesh, A. (1995) 'Marketing in a postmodern world', European Journal of Marketing, Vol. 29, No. 1, pp.40-59.

Gregory, M. (2011) Toyota Prius Sales in the US Reach One Million Mark [online] $\mathrm{http}: / /$ americanfuels.blogspot.com/2011/04/toyota-prius-sales-in-us-reach-one.html.

Hagel, J. III and Brown, J.S. (2008) 'From push to pull: emerging models for mobilizing resources', Journal of Service Science, Vol. 1, No. 1, pp.93-110.

Heidegger, M. (1977) The Question Concerning Technology, and Other Essays, Harper \& Row, New York.

Hidas, P. (2007) Svimlende, mystiske Google, 4 May [online] http://www.idg.no/bransje/bransjenyheter/article57876.ece (accessed 12 February 2013).

Hill, R.P. (2002) 'Managing across generations in the 21st century: important lessons from the ivory trenches', Journal of Management Inquiry, Vol. 11, No. 1, pp.60-66.

Hughes, T.P. (2004) Human-Built World: How to Think About Technology and Culture, University of Chicago Press, Chicago.

Illich, I. (1973) Tools for Conviviality, Harper \& Row, New York.

ITU (2010) The World in 2010: ICT Facts and Figures, International Telecommunication Union, Geneva.

Latour, B. (1987) Science in Action: How to Follow Scientists and Engineers Through Society, Harvard University Press, Cambridge, Mass.

Lazarus, A.A. (1989) The Practice of Multimodal Therapy, Johns Hopkins University Press, Baltimore, MD.

Lazarus, A.A. (1997) Brief But Comprehensive Psychotherapy: The Multimodal Way, Springer, New York.

Lévi-Strauss, C. (1966) The Savage Mind, University of Chicago Press, Chicago.

Li, Q. (2007) 'New bottle but old wine: a research of cyberbullying in schools', Computers in Human Behavior, Vol. 23, No. 4, pp.1777-1791. 
McCarthy, I.P., Lawrence, T.B., Wixted, B. and Gordon, B. (2010) 'A multidimensional conceptualization of environmental velocity', Academy of Management Review, Vol. 35, No. 4, pp.604-626.

Miller, C.C. (2010) 'E-books top hardcovers at Amazon', The New York Times, 19 July [online] http://www.nytimes.com/2010/07/20/technology/20kindle.html (accessed 12 February 2013).

Nielsen (2010) Nielsen NetView - June 2009-June 2010, Nielsen.

Pitt, L.F., Berthon, P.R., Watson, R.T., Wynne, D. and Strasheim, A. (2007) 'Open to all: a postmodern perspective on product development and brands in an open-source environment', International Journal of Technology Marketing, Vol. 2, No. 4, pp.316-326.

Polanyi, K. (2002/1944) The Great Transformation the Political and Economic Origins of Our Time, Beacon Press, Boston, Mass.

Polanyi, M. (1970) 'Transcendence and self-transcendence', Soundings, Vol. 53, No. 1, pp.88-94.

Royle, E. (2005) 'E-gad!', Smithsonian Magazine (Smithsonian Institution) [online] http://www.smithsonianmag.com/arts-culture/e-gad.html (accessed 17 March 2009).

Shenk, D. (1997) Data Smog: Surviving the Information Glut, Harper Edge, San Francisco, California.

Toffler, A. (1980) The Third Wave, Morrow, New York.

Toffler, A. (1983) Previews and Premises, William Morrow and Company, New York.

Twenge, J.M. and Campbell, W.K. (2009) The Narcissism Epidemic: Living in the Age of Entitlement, Free Press, New York.

Xie, C., Bagozzi, R. and Troye, S. (2008) 'Trying to prosume: toward a theory of consumers as co-creators of value', Journal of the Academy of Marketing Science, Vol. 36, No. 1, pp.109-122. 